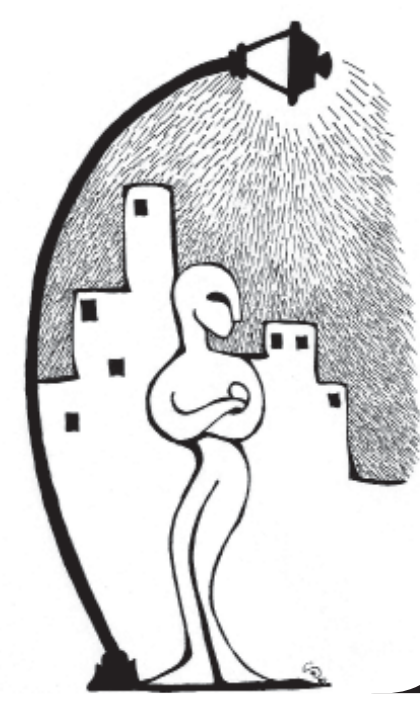

\title{
Lima o la poesía de lo cotidiano
}

\section{Jorge Wiesse}

veces tenemos la fantasía de querer identificar la poesía con sus procedimientos: el verso, la rima, un tipo de lengua especial (decir «cogí la pluma» por «escribir», por ejemplo). Ello hace que muchas veces la lengua hable por el poeta y que los recursos se sobrepongan al contenido. En realidad, forma y contenido son indesligables en el arte. Por eso, el dejarse llevar por un tipo de lenguaje o un tipo de organización artística puede matar la verdadera experiencia estética.

En setiembre de 2005, la editorial Laberintos publicó mi poemario Vigilia de los sentidos. En él no quise ceñirme a un solo tipo de forma, sino jugar con varias. Están, por supuesto, las formas tradicionales (muchas de las composiciones son sonetos), pero también hay verso libre, y, en algunas partes, prosa. Hacia el final del poemario, puede encontrarse un conjunto de textos breves (algunos en verso, algunos en prosa) a los que titulé Lima. Se trata de 12 composiciones que, de manera libre, tratan de dar cuenta de una especie de «ruta temporal»: el curso de una experiencia que se dilata a lo largo de un año en una ciudad.

La ruta empieza en abril y termina en marzo. Coincide libremente con el calendario del zodíaco. Y los distintos momentos tratan de capturar la experiencia fugaz del instante. Son, en este sentido, textos líricos, textos poéticos, aunque no estén en verso, pues, como toda lírica, son la captación de lo que podría denominarse un «instante trágico», es decir, el punto donde lo bello y lo fugaz se juntan para producir conciencia de la finitud, del ser finito, la conciencia de que no somos eternos, y, a la vez, el deseo de absoluto, el deseo de fijar un momento como absoluto. Es trágico, porque nuestra experiencia está sometida al 
tiempo y a la muerte, y es heroico, porque aun sabiéndolo queremos fijar lo fugaz, volver absoluto al instante.

Me interesa mostrar estas composiciones porque capturan la experiencia de lo cotidiano. Algunos espacios están ligados a mi infancia, otros a mi vecindad, otros a las rutas que hago para ir a mi trabajo.

La serie Lima está encabezada por «Abril» y cerrada por «Playa». Entre ambas, hay 10 composiciones en prosa, 10 prosas líricas. Como veremos con mayor detalle, lo fundamental es la idea (o mejor: las imágenes) de lo cíclico, de lo recurrente, de lo que vuelve sin la participación del sujeto. Se trata de una paradoja, obviamente: hay el deseo de capturar una experiencia subjetiva, fuertemente personal, pero a la vez existe la conciencia de que todos los objetos y los espacios a los que se refieren los textos sobrevivirán al autor o al sujeto de los textos.

Empiezo por la lectura de «Abril»:

ABRIL

\author{
Cuando yo ya no esté, \\ La flor del ceibo \\ Seguirá envuelta \\ En la garúa \\ De la mañana; \\ Las hojas de los ficus \\ Temblarán todavía \\ $\mathrm{Al}$ vaivén suave \\ De la tarde temprana; \\ $Y$ la luz dulce \\ Que viene del oeste \\ Volverá a herir \\ Los iris de tus ojos. \\ Cuando yo ya no esté.
}

Pensé este poema a la manera (o, mejor, en el espíritu) de Bécquer: alternancia de versos de 5 y de 7 sílabas, la preferencia por lo impar, por la alternancia de versos de metros (o cantidades) próximos; repetición del mismo verso al principio y al final del poema; asonancia (mañana, temprana) que puntúa las diversas partes del día: el poema se refiere a 
la mañana, a la tarde temprana y a la tarde "tardía», la del ocaso, la de la puesta de sol. Y, sobre todo, la repetición: «cuando yo ya no esté», que se contrapone paradójicamente a la secuencia lineal del día y sugiere, con su «vuelta», con su reiteración, que ese día se repetirá, pero que la presencia del sujeto que lo goza, no.

El siguiente texto es «Casas»:

\section{CAsas}

En la casa de Lártiga, los bloques sombríos del zaguán, que amortiguan los pasos y los vuelven íntimos, se desperdigan, detrás de la cancela, en un infinito simétrico de cantos rodados caldeados por la luz de la tarde que acaricia, a través del prisma de los cristales, los alineados volúmenes que guardan los anaqueles de la biblioteca. Ante El Carmelo, los espejeos del agua quiebran la gloria del cielo: hace tiempo que allí dejó de escucharse el ritmo de las piedras lavadas por el mar.

Aquí me interesa destacar tanto las diferentes partes de la casa Riva-Agüero (que tan bien recoge un dibujo de Ricardo Ramírez) como la idea de "fusión»: un objeto se continúa en el otro por la magia de la sintaxis. Sí, todos los profesores, y yo mismo, les dirán a sus alumnos que deben escribir con oraciones cortas. Pero la oración larga me permite en este caso fundir un objeto en otro y crear, por contigüidad, posibilidades metafóricas, imaginativas. Pensemos, por ejemplo, en este caso en la imagen de la piedra. Las piedras tienen distintos valores a lo largo del texto. $\mathrm{Y}$ en un momento, son semejantes a los libros. Si contrasto esta identidad con lo que se dice en la segunda oración y compruebo que las piedras estuvieron un tiempo lavadas por el mar, pero que ya no están, comprobaré que los libros también pueden desaparecer, que el saber que guardan es un saber precario y que el tiempo, como el mar, puede hacer que quede en el olvido. 


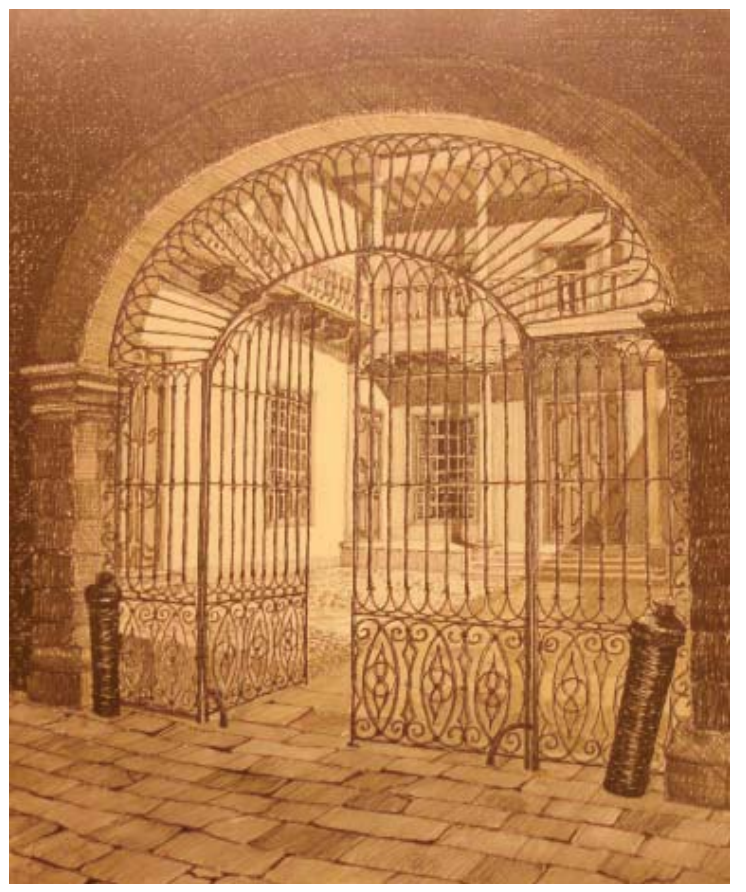

Instituto Riva-Agüero. Dibujo (tinta) de Ricardo Ramírez. 1982 
Sigue la prosa «Jardín»:

JARDín

A Leopold G. Palm

\begin{abstract}
Y, súbitamente, ante una eternidad de duna y roca, brotaron flores de tu cuerpo generoso. Y el silencio intentó acercarse a la música.
\end{abstract}

El jardín al que se refiere la prosa "Jardín» es el cementerio Jardines de la Paz, en La Molina. Como lo sabe quien lo ha visitado, es un proyecto de reforestación: el jardín contrasta fuertemente con la arena y la piedra de la geografía circundante. La imagen de las flores que brotan del cuerpo generoso evoca el ataúd sobre el que se colocaron arreglos florales el día del entierro. Mi amigo Leopold era músico. De ahí la experiencia sobrecogedora de su muerte, vista como el intento del silencio (la muerte) de aproximarse a la música (Leopold). Pero la muerte se queda en el intento. Las flores y el recuerdo se oponen, tensamente, a su muerte absoluta.

A continuación, el texto «Sábado»:

\title{
SÁBADo
}

Mientras el pentagrama se va reflejando en el teclado fugaz, una rosa tiembla solitaria en el fondo acuoso del espejo... De pronto, el inquieto diseño de unas cuantas notas ocultas bajo la corriente hace huir a la romanza sin palabras hacia aquel intermezzo cuyo son, años atrás, llegó a medirse con el movimiento furioso del mar de Tuquillo. 
«Sábado» remite a una situación que era frecuente los sábados por las tarde en casa de Carlos Gatti, cuando sus amigos podían oírlo tocar piano. En la casa de Pueblo Libre donde Carlos vivía, la sala en que estaba el piano Bechstein tenía un espejo que reflejaba el rosal del jardín exterior. En la prosa, esa imagen se funde con la del pentagrama reflejado en el teclado (en el sentido en que el intérprete ejecuta aquello escrito en el pentagrama, pero también en el sentido en que las teclas se reflejan en el barniz del propio piano). La música que surge de una romanza sin palabras de Félix Mendelssohn se mezcla (por afinidad misteriosa) con el recuerdo del Intermezzo del Carnaval de Viena de Robert Schumann, que a su vez evoca un breve paseo hecho en 1972 a la playa norteña de Tuquillo, cercana a Huarmey. En ese paseo, Úrsula Ramírez llevó en un tocacasete la música del Intermezzo, que oíamos todos en contraste al fuerte oleaje del mar de esa zona. El «movimiento furioso» evoca la Canción V de Garcilaso de la Vega en la que se habla de la música que puede aplacar la furia y el movimiento del mar ( «Si de mi baja lira / tanto pudiera el son que en un momento / aplacase la ira / del animoso viento / y la furia del mar y el movimiento»).

«Muro» es el texto que sigue a «Sábado»:

\section{Muro}

Como un pasado visto de frente, la calle va desapareciendo envuelta en el olvido progresivo de la cerrada niebla de la noche. A lo largo de un largo muro, los fogonazos de la lluvia de oro parecen recoger, tercos, las luces intensas de otras tardes y de otras auroras.

Este muro está muy cerca de mi casa. Es el muro del Colegio Santa Úrsula, en San Isidro. La experiencia concreta se refiere a una noche de invierno en donde la niebla estaba tan baja y tan densa que prácticamente se veían en la noche solo los fogonazos de la lluvia de oro o cahuato, una enredadera que puede encontrarse en varias partes de Lima. La fusión aquí es con el recuerdo: una vida es como un muro, en tanto es una continuidad de recuerdos, recuerdos que son como los soles de los días, o de los atardeceres de los días. Los soles-recuerdos están amenazados por la noche-olvido. Pero se mantienen tenaces. 


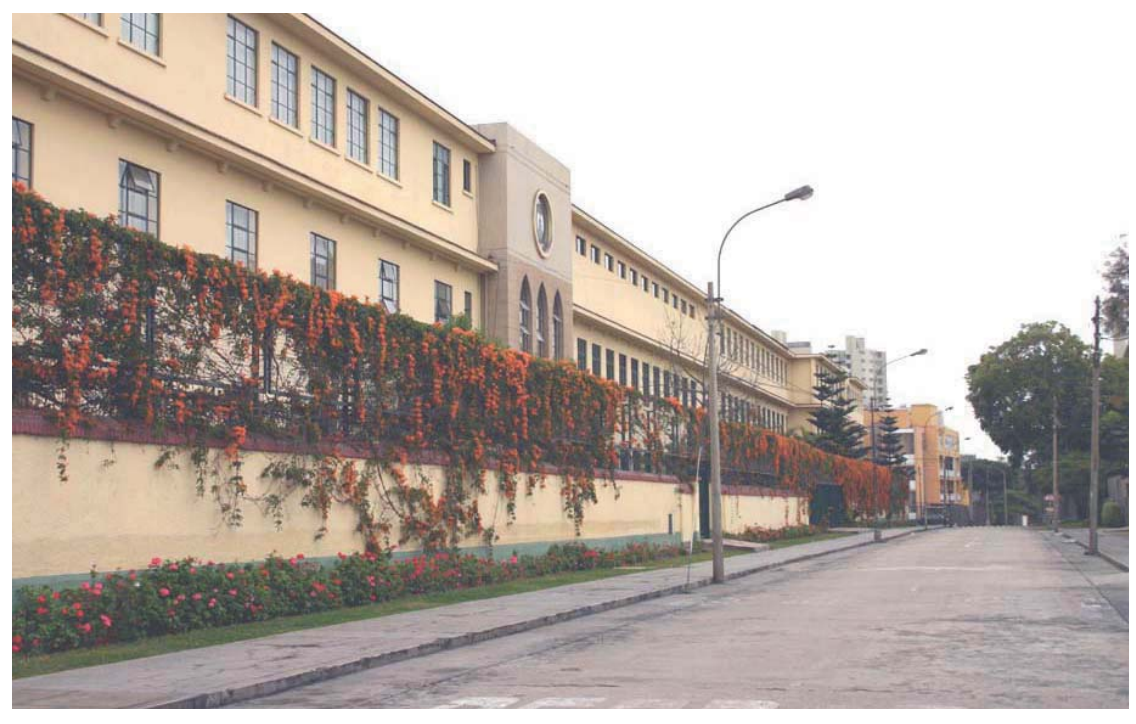

Muro del Colegio Santa Úrsula, San Isidro. Fotografía de Jimena Ramírez 
El sexto texto es «Huacas»:

Huacas

¿Y si la procesión de vagas humedades que un sol oculto enciende intermitentemente en los espacios que se elevan sobre la banda alta y sombría de Tres Palos no fuera sino el deseo prolongado de que no quede abolido el instante aquel cuando, de un mar y un cielo acerados, surgió San Lorenzo, como una idea solitaria, envuelta en un dorado capullo de nubes?

Huacas funde dos momentos, que se presentan invertidos cronológicamente. El primer momento es el de la visión de la isla de San Lorenzo desde lo alto de la bajada de San Isidro: en una mañana de verano, la isla de San Lorenzo apareció envuelta en niebla. La niebla estaba focalizada en la isla. El resto del cielo estaba parejo, acerado. La niebla sobre San Lorenzo era una niebla dorada porque el sol hacía que la refracción fuera intensísima. Era un ovillo dorado, un fanal de niebla y oro. El segundo momento evoca la visión de la Huaca Tres Palos desde la calle río Urubamba. Es mi ruta para ir desde la Universidad del Pacífico hasta la Pontificia Universidad Católica. Al doblar para entrar a río Urubamba se aprecia la silueta inmensa de la huaca recortada contra el cielo y sobre ella las nubes que pasaban en copos enormes, como en un desfile. Y detrás de ellas, el sol que las iluminaba. Se me ocurrió, entonces, que esas nubes no eran sino ensayos (porque también eran ovillos de humedad y sol) que buscaban prolongar la maravillosa visión del San Lorenzo dorado del verano. Tanto Tres Palos como San Lorenzo son importantes sitios arqueológicos, son huacas. Ambos evocan esa maravillosa combinación de humedad y desierto que constituye la experiencia del paisaje de la costa peruana. 
Viene, luego, «Otoño»:

\section{Оток̃o}

Como hojas secas, los pájaros se desprenden del ficus para sumirse, mudos, en un frío blanco y sucio.

Esta prosa corresponde a la siguiente experiencia: yo estaba en un aula del segundo piso del edificio de Estudios Generales Letras de la Pontificia Universidad Católica. Era el aula del extremo, la más cercana al estacionamiento. Seguramente era uno de esos tiempos muertos vitales: el interés de la clase había decaído, o estaba cuidando un control (me parece difícil que pudiera tratarse de un examen). Y de pronto, de la magnificencia opaca del ficus, empezaron a salir los pájaros, no en bandadas, sino casi uno a uno, o en grupos muy pequeños. A lo lejos, el árbol se había transformado en un surtidor de pájaros que desaparecían en esa dimensión desconocida que es el cielo limeño. Aunque puede ser que recuerde mal: que el árbol no fuera un ficus o que este no se encontrara en los extremos del estacionamiento de Estudios Generales. Podría ser que fuera otro árbol. Pero de lo que sí estoy seguro es que fue un árbol de los jardines de Pando. Y que lo vi o desde el aula o en el pasillo.

Titulé «Invierno» al texto que sigue:

\section{INVIERNO}

el cielo sin cielo de mi ciudad

Sebastián Salazar Bondy

Abajo, árboles como corales sin color. Arriba, solo la inquieta

puntuación de unas cuantas aves rompe el equívoco entre

mar y cielo.

«Invierno» podría referirse al cielo de cualquier parte de Lima. «El cielo sin cielo de mi ciudad», como tan justamente lo describe Sebastián Salazar Bondy, es una variante 
marina: árboles como corales opacos, abajo, y cielo como mar, arriba. El equívoco, la confusión entre mar y cielo, solo es aclarado por las aves. La "puntuación» de estas evoca, además, la página en blanco del poeta o el lienzo vacío del artista plástico.

«Jesús María» evoca una infancia y una Lima idas, pero encapsuladas en un espacio limitado y en la memoria:

\section{Jesús María}

A R.W.T.

Limpios los zapatos del barro pringoso de la calle, los pasos resuenan en una oscuridad poblada por presencias vegetales mientras sus ecos se mezclan con la monótona fioritura de una oración murmurada al otro lado de la clausura. Central y recogida, como los verdes fuegos en las matas umbrías, brilla el ascua de la custodia. La infancia es una voluta turífera que se desvanece en la nada del aire de una mañana de invierno.

Esta composición se refiere a la iglesia barroca de Jesús, María y José, que queda en la esquina de los jirones Moquegua y Camaná, en el centro histórico de Lima. Como lo sabe cualquier limeño, en Lima no llueve, pero la fina garúa invernal que hace las veces de la lluvia deja en las calles la suficiente cantidad de agua como para que se produzca un barro que se pega a las suelas de los zapatos y que hay que limpiar antes de entrar a casas o iglesias. La prosa reproduce el ingreso a la iglesia y el recorrido hacia el altar y la custodia. La iglesia está separada del convento de clausura de las Madres Capuchinas por una reja que deja salir el murmullo de una oración. Al final, se sale, luego del recuerdo infantil (la iglesia fue el escenario de mi primera comunión, de la de mis hermanos, de la de mis primos, y, más recientemente, de mis sobrinos, entre otras actividades generadas por la presencia de mi tío Ricardo, que es sacerdote). Y el recuerdo de la infancia desaparece como el humo del incienso en medio del aire incoloro del invierno. Una evocación literaria vinculada con lo barroco de la iglesia: el soneto «Mientras por competir con tu cabello» de Góngora. Los elementos de la enumeración del último verso del soneto (tierra, humo, polvo, sombra, nada) están evocados a lo largo de la prosa (el humo y la nada forman parte de la última oración, por ejemplo). 
El siguiente texto se refiere a una situación primaveral:

\begin{abstract}
Árbol
La copa es una vaga nube de infinitos que al imponer la pompa de su día a esta noche de primavera parecen querer volver menos inminente un mañana desperdigado y marchito.
\end{abstract}

El árbol al que alude la prosa es un jacarandá que puede verse en el jardín del colegio Santa Úrsula de San Isidro cuando se camina por la calle Víctor Andrés Belaunde. Rara vez está iluminada, pero lo estuvo en la noche de noviembre en que lo vi como una gran nube azul (el color de las flores del jacarandá). Y estaba tan bellamente iluminado por un reflector (que, con buen gusto, no se veía) que parecía un día azul rodeado de una noche negra. De ahí el deseo de que permanezca, aun cuando se sabe que las flores se caerán y se marchitarán desperdigadas en el suelo que está debajo del árbol.

La prosa que sigue se refiere al último mes del año y a la inminencia del verano:

\title{
DiCIEMBRE
}

Umbral del verano: de mañana, espolvoreadas sobre una noche verde a la que oprime un cielo plúmbeo, las flores de las tipas — rescoldos de estrellas — plantan en el aire quieto que las roza las semillas del fondo de oro de los lienzos de la tarde.

«Diciembre» quiere evocar la experiencia de un paseo matinal por la avenida Santo Toribio, en San Isidro. En diciembre los árboles de esa avenida, enormes tipas, se llenan de flores amarillas. Un cielo cargado de humedad contrasta con el verde y con el amarillo. Es la 
garantía, además, de los bellos crepúsculos limeños, «los lienzos de la tarde», tan justamente elogiados por Herman Melville en Moby Dick.

Finalmente, el verano, en «Playa»:

\section{Playa}

Besan esas brisas vanas

El borde del agua.

Un brillo el día concentra

Y tiembla en la öla crespa

Al borde del agua.

Aletea un ave huida;

Se apaga el rumor del día

Al borde del agua.

Una fina brisa borra

Al día y a su memoria

Al borde del agua.

Besan esas brisas vanas

El borde del agua.

"Playa», como ya lo indiqué, es el último texto de la serie «Lima». La playa a la que se refiere es la playa de Miraflores. El poema trata de capturar los últimos momentos del verano. Nuevamente, como en el poema «Abril», que abre la serie, se presentan los diversos momentos del día (el «día concentrado» de la segunda estrofa alude al mediodía, luego sigue la tarde crepuscular y finalmente, lo último de la tarde). Aquí, en contraste con «Abril», la repetición se hace mayor (se repite la estrofa inicial al final, hay un estribillo en cada estrofa y el ritmo es fuertemente musical). El borde del agua es imagen o metáfora fuerte. En efecto, si nuestras vidas son los ríos «que van a dar en la mar que es el morir», como dice 
Jorge Manrique, el mar es imagen de la muerte y estar al borde de él es estar contemplando el misterio de la fragilidad y la belleza de la vida.

Sí, Lima es poesía de lo cotidiano, pero como la geografía lírica de Antonio Machado, mezcla, en este caso, lo «esencial limeño» con lo universal humano. Si bien solo algunos lectores reconocerán la experiencia que ella evoca como limeña, espero que todos la reconozcan como humana. 

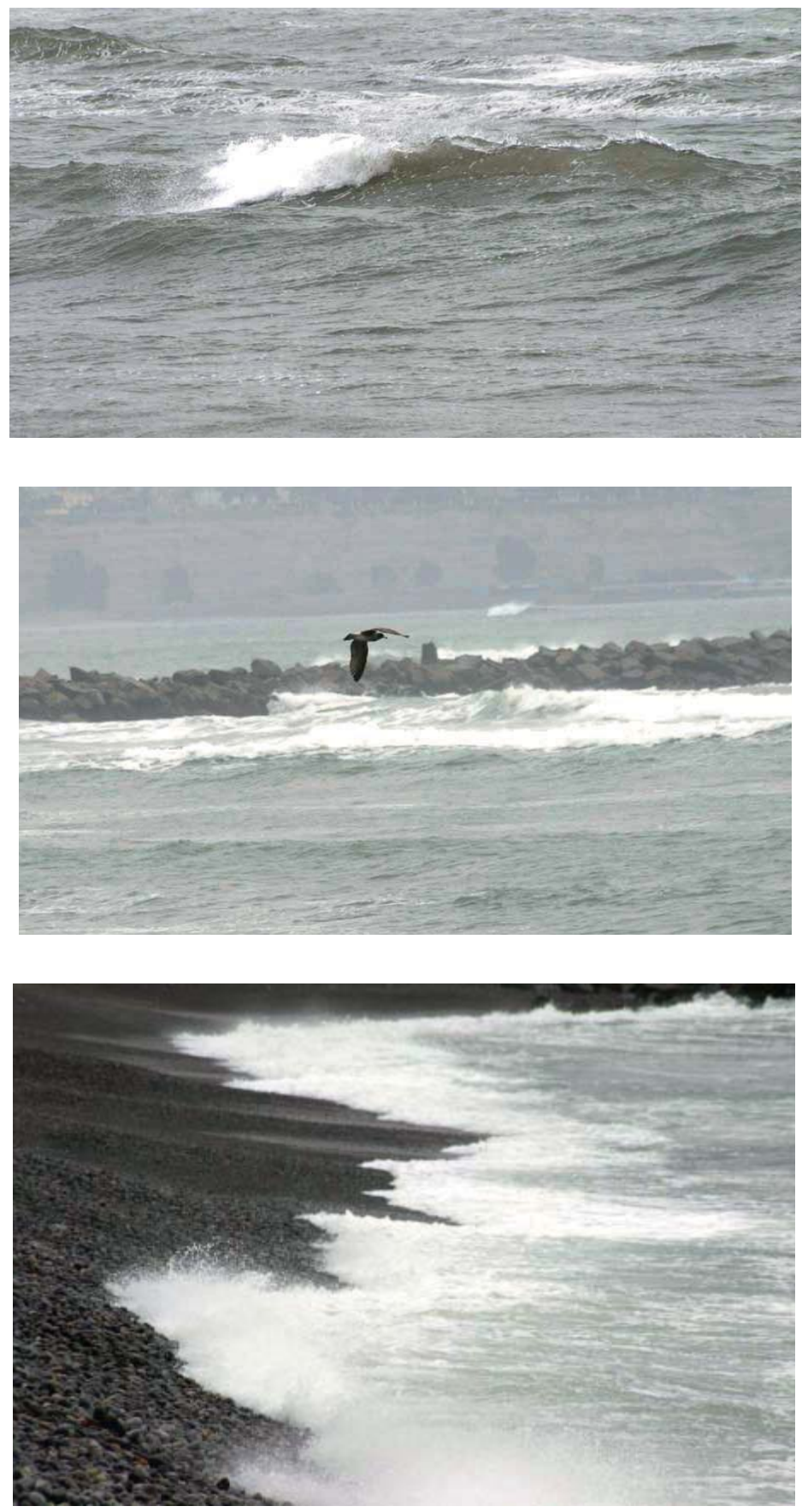

Playa de Miraflores. Fotografías de Manuel Vinatea

188 CUADERNOS LITERARIOS 